\title{
RP-HPLC analysis of phenolic antioxidant compound 6-gingerol from in vitro cultures of Zingiber officinale Roscoe
}

\author{
Nilesh Pawar ${ }^{1}$, Sandeep Pai ${ }^{2}$, Mansingraj Nimbalkar ${ }^{3}$ and Ghansham Dixit ${ }^{3}$
}

\begin{abstract}
Relation between 6-gingerol content and antioxidant activity in in vitro grown cultures of ginger was studied. Reverse phase HPLC analysis revealed that rhizome derived callus culture and micropropagated plants produced lowest amount of 6-gingerol compare to conventionally grown plants. The antioxidant activity of extracts was determined using 1,1-diphenyl-2-picrylhydrazyl (DPPH) radical scavenging assay and Ferric Reducing power assay (FRAP) and correlated with the content of total phenolics and total flavonoids in the extracts. Strong correlation was found between antioxidant activity, total phenolics and 6gingerol content.
\end{abstract}

Keywords: HPLC; Ginger; 6-gingerol; antioxidant activity; callus

Received: 15 November 2014

Accepted revised version: 19 December 2014

Published online: 1 January 2015

(C) Pawar et al. (2015)

Publisher: Horizon e-Publishing Group

CITATION

Pawar, N., S. Pai, M. Nimbalkar, and G. Dixit. 2015. RP-HPLC analysis of phenolic antioxidant compound 6-gingerol from in vitro cultures of Zingiber officinale Roscoe. Plant Science Today 2: 24-28. doi: 10.14719/pst.2015.2.1.103

AUTHOR'S AFFILIATION

1 Department of Botany, The New College, Kolhapur - 416012 (MS) India

2 Regional Medical Research Centre, ICMR, Belgaum (Karnataka) India

3 Department of Botany, Shivaji University, Kolhapur - 416004 (MS) India

CORRESPONDENCE

\Dr. Nilesh Pawar Email: nileshsu@gmail.com

\section{Introduction}

The rhizome of ginger (Zingiber officinale, Rosc.) Zingiberaceae has long served culinary and medicinal uses (Afjal et al., 2001). It has been used as a spice for over 2000 years (Bartley and Jacobs, 2000). Its roots and the obtained extracts contain polyphenol compounds (6-gingerol and its derivatives), which have a high antioxidant activity (Chen et al., 1986; Herrmann, 1994). Two major groups of compounds including gingerol-related compounds and diarylheptanoids have been reported as bioactive components from this plant (Koo et al., 2001; Masuda et al., 2004). Gingerols and shogaols give ginger its pungency and consist of a homologous series of aldols each containing a phenolic group. Its major pungent constituent, [6]-gingerol has been reported to exhibit antioxidative activity against linoleic acid autoxidation and peroxidation of phospholipid liposomes and to scavenge trichloromethylperoxyl- and 1,1diphenyl-2-picrylhydrazyl (DPPH) radicals (Aeschbach et al., 1994; Sekiwa et al., 2000; Pawar et al., 2011). In addition to these antioxidative effects, our recent study (Ippoushi et al., 2003; Ippoushi et al., 2005) revealed that [6]-gingerol inhibits nitric oxide synthesis in activated J774.1 macrophages and prevents oxidation and nitration reactions induced by peroxynitrite (Radi et al., 2001), a strong reactive nitrogen species. The purpose of this study was to assess the antioxidant activities and to determine 6- gingerol content from the different in vitro ginger extract.

\section{Material and methods}

\section{Plant material sterilization and inoculation of explant}

Rhizome shoot explant was washed with solution of laboline and rinsed thoroughly with distilled water. After the treatment of $0.1 \% \mathrm{HgCl}_{2}$ for 6 minutes, the explants were given three to four washes of sterilized double distilled water and blotted well on a sterilized tissue paper. The rhizome explant cut to appropriate size and cultured aseptically on MS medium 
(Murashige and Skoog, 1962) supplemented with different concentrations of 2,4-dichlorophenoxyacetic acid (2,4-D) and NAA for callus induction and IAA and BAP for shoot multiplication. The cultures were maintained on similar media compositions and sub-cultured after every four weeks for shoot multiplication. Plants were removed for hardening after 6 subculture and transplanted in open field. After a period of 45 days, established callus was taken up for quantification of 6-gingerol.

\section{Extract Preparation}

Rhizome of conventionally grown plant and in vitro grown plant was removed from field and washed with tap water and then rinsed with double distilled water. Rhizomes along with calli were dried under oven for $60^{\circ} \mathrm{C}$ and pulverized separately. The one gram of powder of rhizome/calli from each treatment was dissolved in $25 \mathrm{ml}$ methanol and sonicated for 30 minutes. The mixture was centrifuged at 10,000 rpm for 10 minutes and the supernatant was filtered through Whatmans filter paper no.1. All these extracts were kept at $4{ }^{\circ} \mathrm{C}$ and for assay diluted extracts were used.

\section{Quantification of Total Phenolic Content (TPC)}

Total phenolic content was quantified using modified Folin - Ciocalteu method described by (Wolfe, Wu, and Liu, 2003). The assay mixture was prepared using $0.125 \mathrm{ml}$ different concentrations of standard Tannic acid with $0.250 \mathrm{ml}$ of Folin Ciocalteu reagent, $1.25 \mathrm{ml}$ of distilled water and incubated for $10 \mathrm{~min}$ in dark. After $10 \mathrm{~min}, 1 \mathrm{ml} 7 \%$ aq. sodium carbonate and $1 \mathrm{ml}$ of distilled water is added and the reaction mixture is incubated in dark for $90 \mathrm{~min}$ at $37^{\circ} \mathrm{C}$. The absorbance of blue colour was read at $760 \mathrm{~nm}$ using distilled water instead of std. tannic acid in the reaction mixture as blank on double beam spectrophotometer. Similarly, extracts prepared were also quantified and the results were compared to the standard curve of above standards and expressed as mg/Tannic or equivalent per gram dry powder for the samples under study.

\section{Quantitative determination of total flavonoid contents}

Total flavonoid contents in all the above extracts were determined by using a method given by (Luximan - Ramma et al., 2002). 1\% plant extract ( $1.5 \mathrm{ml}$ ) was taken for the determination of total flavonoids. To this, $1.5 \mathrm{ml}$ of $2 \%$ aluminium chloride in methanol was added. The reaction mixture was incubated for 10 minutes at room temperature. The OD was measured at $368 \mathrm{~nm}$ against $2 \% \mathrm{AlCl}_{3}$, as blank. The OD measurements were compared to standard curve of Quercetin (a standard flavonoid) concentrations and expressed as milligrams of Quercetin equivalent per gram dry weight of ginger.

Antioxidant activity: DPPH 2-Diphenyl-1-picrylhydrazyl) assay

The antioxidant activities were determined as the measure of radical scavenging using DPPH assay as determined by (Brand-Williams et al., 1995). Three ml of a methanolic solution of DPPH (25ppm) was mixed with $20 \mu \mathrm{l}$ of different concentration of standard Ascorbic acid and the mixture was incubated for $30 \mathrm{~min}$ in dark. The absorbance at $515 \mathrm{~nm}$ was measured using methanol as blank. The inhibition percentage of DPPH (\% $\%$ DPPH) was calculated and the results were expressed as ascorbic acid equivalent antioxidant capacity (AEAC) as per method described by (Gil et al., 2000).

\section{Antioxidant activity: Ferric Reducing Antioxidant Power (FRAP)}

The ferric reducing/antioxidant power (FRAP) assay was used to measure the total antioxidant power ginger extracts. In the FRAP assay, reductants (antioxidants) in the sample reduce $\mathrm{Fe}^{3+}$ /tripyridyltriazine complex, present in stoichiometric excess, to the blue colored ferrous form, with an increase in absorbance at 593 $\mathrm{nm}$. The $\Delta A$ is proportional to the combined (total) ferric reducing/antioxidant power (FRAP value) of the antioxidants in the sample. Antioxidant activity assays were performed by the method described by (Benzie and Strain, 1996). The results were expressed as

Table 1. Showing activities of DPPH and FRAP in mM and content of Phenolic, Flavonoid and 6-gingerol in \%

\begin{tabular}{|c|c|c|c|c|c|}
\hline Particulars & 6-gingerol & DPPH & FRAP & $\begin{array}{c}\text { Total } \\
\text { phenols }\end{array}$ & $\begin{array}{c}\text { Total } \\
\text { Flavonoids }\end{array}$ \\
\hline Conventional rhizome & 0.165 & 1.493 & 2.732 & 1.578 & 1.422 \\
\hline Callus & 0.056 & 0.720 & 1.680 & 0.648 & 0.753 \\
\hline Micropropagated rhizome & 0.078 & 0.845 & 1.901 & 0.790 & 0.772 \\
\hline
\end{tabular}



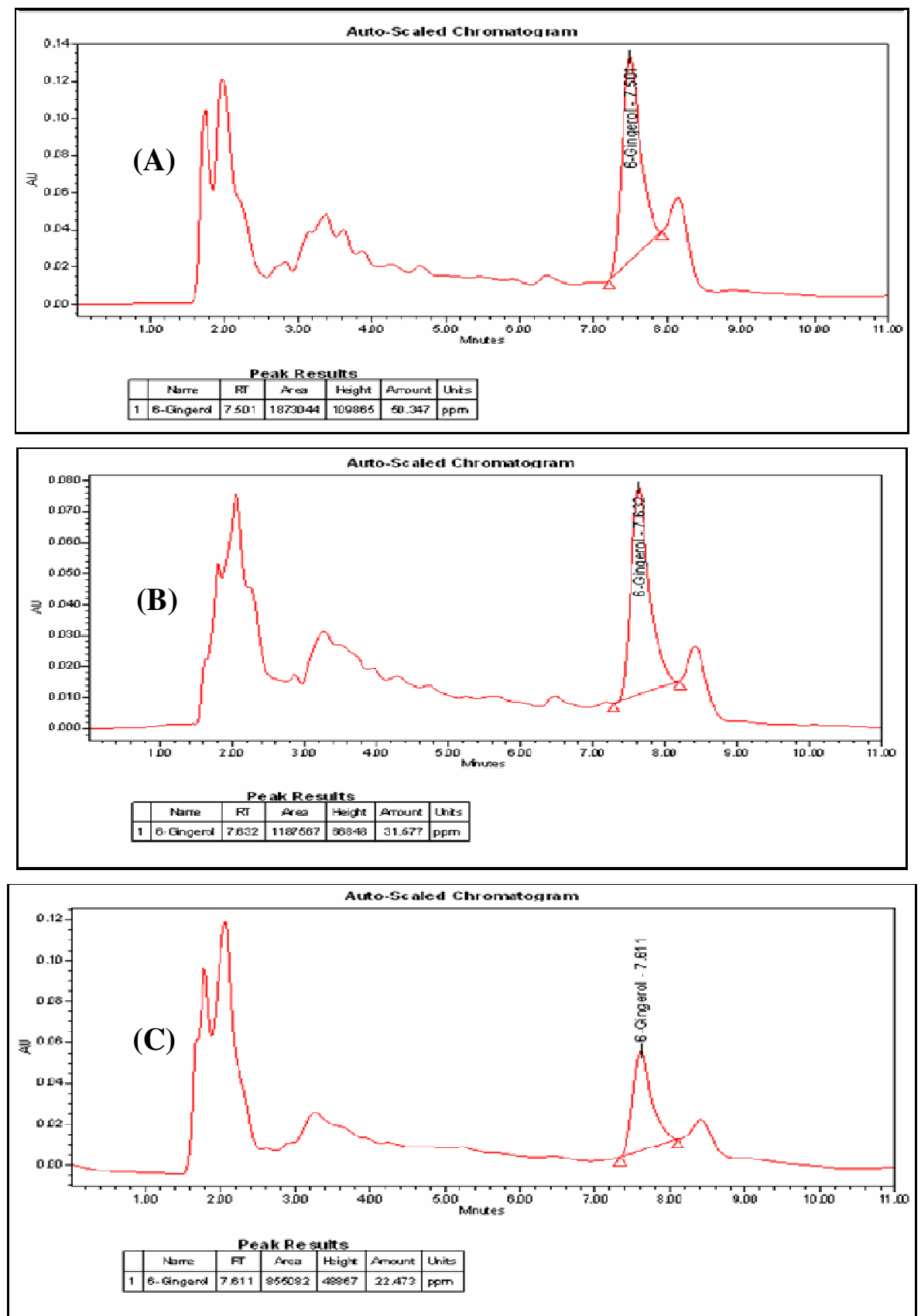

Fig. 1. Chromatograms: A: Conventional rhizome, B: Micropropagated rhizome and C: Callus

ascorbic acid equivalent antioxidant capacity (AEAC).

\section{Results and Discussions}

\section{HPLC analysis for 6- Gingerol content}

Using HPLC analysis, callus, micropropagated rhizome and conventionally grown rhizome were investigated for 6-gingerol content (Fig. 1A to 1C). Which revealed that concentration of 6-gingerol was three fold more $(0.16 \%)$ in conventionally grown ginger rhizome than callus (0.056) and about half
(0.078) in micropropagated plant rhizome (Table 1). Results are in accordance with tissue cultural studies in Camptotheca acuminata by (Sakato and Misawa, 1974) which yielded very less amount Camptothecin from the suspension cultures. Similarly, (Wiedenfield et al., 1997) in callus cultures of C. accuminata and (Roja, 2008) in Shoot cultures of Ophiorrhiza rugosa has reported low amount of Camptothecin. The in vitro grown rhizome has lowest 6- gingerol content because, developing normal size of rhizome comparable to that 
of mother plants requires three year (Nirmal Babu, 1997).

\section{Antioxidant activities, total phenolic and total flavonoid content}

The highest phenolics content found to be in conventionally grown rhizome sample $(1.57 \mathrm{gm} / 100 \mathrm{gm}$ of dry weight) compared to callus $(0.648 \mathrm{gm} / 100 \mathrm{gm}$ of dry weight) and micropropagated grown ginger rhizome $(0.79 \mathrm{gm} / 100 \mathrm{gm}$ of dry weight). Similar results were obtained for total flavonoid content which was expressed in Quercetin equivalent. Highest content (1.44gm/100gm of dry weight) of flavonoid was in conventionally grown rhizome sample followed by micropropagated rhizome sample $(0.77 \mathrm{gm} / 100 \mathrm{gm}$ of dry weight) and lowest was in callus sample $(0.75 \mathrm{gm} / 100 \mathrm{gm}$ of dry weight). The conventionally propagated plants exhibited highest antioxidant activity compared to in vitro cultures. The highest DPPH and FRAP activity was recorded in conventionally grown plant while in micropropagated plant it was 845.34 and $1901.09 \mu \mathrm{M}$ Ascorbic acid eq. respectively and lowest activity was recorded in callus sample. Present results matches with (Grzegorczyk et al., 2007) work on Salvia officinalis L. Correlation between all the traits was above $R^{2}=0.90$. Strong correlation was found between Phenolic and DPPH $\left(\mathrm{R}^{2}\right.$ $=0.999)$ and Gingerol and FRAP $\left(R^{2}=0.999\right)$. The trend of increase or decrease of all activities and content was similar for conventionally grown rhizome, micropropagated rhizome and callus.

\section{Conclusion}

As expected, the extracts of callus and micropropagated plants of ginger proved to be less active in all methods tested. It is accepted that the dedifferentiation of plant tissues during establishment of callus and cell cultures is often connected with reduction of content of secondary metabolites. According to our knowledge, there are no detailed data regarding the composition of phenolic compounds in ginger cultures were present. So this preliminary study contributes new knowledge of the composition of phenolic compounds by HPLC analysis. Further studies necessary to explain the differences observed.

\section{References}

Aeschbach, R., J. Lo" liger, B. C. Scott, A. Murcia, J. Butler, and B. Halliwell. 1994. Antioxidant actions of thymol, carvacrol, 6-gingerol, zingerone and hydroxytyrosol. Food and Chemical Toxicology 32: 31-36. doi:10.1016/0278-6915(84)90033-4

Afzal, M., D. Al-Hadidi, M. Menon, J. Pesek, and M, S. Dhami. 2001. Ginger: an ethmomedical, chemical and pharmacological review. Drug Metabolism and Drug
Interactions $18 \quad(3-4): \quad 159 \quad-\quad 190$. doi:10.1515/DMDI.2001.18.3-4.159

Bartley, J., and A. Jacobs. 2000. Effects of drying on flavour compounds in Australian-grown ginger (Zingiber officinale). Journal of the Science of Food and Agriculture 80: 209-215. doi:10.1002/(SICI)1097-0010(20000115)80:2<209:: AID-JSFA516>3.0.CO;2-8

Benzie, I. F. F., and J. J. Strain. 1996. The ferric reducing ability of plasma (FRAP) as a measure of Antioxidant Power': The FRAP assay. Annals Biochemistry 239: 70-76. doi:10.1006/abio.1996.0292

Brand-Williams, W., M. E. Cuvelier, and C. Berset. 1995. Use of a free radical method to evaluate antioxidant activity. Lebensmittel Wissenschaft and Technologie 28: 25-30. doi:10.1016/S0023-6438(95)80008-5

Chen, C. C., M. C. Kuo, C. M. Wu, and C. T. Ho. 1986. Pungent compounds of ginger (Zingiber officinale Roscoe) extracted by liquid carbon dioxide. J. Agric. Food Chem. 34: 477-480. doi:10.1021/jf00069a027

Gil, M. I., F. A. Tomas-Barberan, B. Hess-Pierce, D. M. Holcroft, and A. A. Kader. 2000. Antioxidant activity of pomegranate juice and its relationship with phenolic composition and processing. J. Agric. Food Chem. 48: 4581-4589. doi:10.1021/jf000404a

Grzegorczyk, I., A. Matkowski, and H. Wysokinska. 2007. Antioxidant activity of extracts from in vitro cultures of Salvia officinalis L. Food Chemistry 104: 536-541. doi:10.1016/j.foodchem.2006.12.003

Herrmann, K. 1994. Antioxidativ wiksame Pflanzenphenole sowie Carotinoide als wichtige Inhaltsstoffe von Gewürzen. Gordian 94: 113-117.

Ippoushi, K., H. Ito, H. Horie, and K. Azuma. 2005. Mechanism of inhibition of peroxynitrite-induced oxidation and nitration by [6]- gingerol. Planta Medica 71: 563-566. doi:10.1055/s-2005-864160

Ippoushi, K., K. Azuma, H. Ito, H. Horie, and H. Higashio. 2003. [6]- Gingerol inhibits nitric oxide synthesis in activated J774.1 mouse macrophages and prevents peroxynitrite-induced oxidation and nitration reactions. Life Sciences 73: 3427-3437. doi:10.1016/j.lfs.2003.06.022

Koo, K. L., A. J. Ammit, V. H. Tran, C. C. Duke, and B. D. Roufogalis. 2001. Gingerols and related analogues inhibit arachidonic acid-induced human platelet serotonin release and aggregation. Thrombosis Research 103(5): 387-397. doi:10.1016/S0049-3848(01)00338-3

Luximon-Ramma, A., T. Bahorum, M. A. Soobrattee, and O. I. Aruoma, 2002. Antioxidant activities of phenolic, proanthocyanidin and flavonoid components in extracts of Cassia fistula. J. Agric. Food Chem. 50: 5042-5047. doi:10.1021/jf0201172

Masuda, Y., Kikuzaki, H. Hisamoto, M. and Nakatani, N. 2004. Antioxidant properties of gingerol related compounds from ginger. Biofactors 21: 293-296. doi:10.1002/biof.552210157

Murashige, T., and F. Skoog. 1962. A revised medium for rapid growth and bioassays with tobacco tissue culture. Physiologia Plantarum 15: 473-497. doi:10.1111/j.1399-3054.1962.tb08052.x 
Nirmal Babu, K. 1997. In vitro studies in ginger, Zingiber officinale Rosc. Ph.D. Thesis, University of Calicut, Kerala, India.

Pawar N., S. Pai, M. Nimbalkar, and G. Dixit. 2011. RP-HPLC analysis of phenolic antioxidant compound 6-gingerol from different ginger cultivars. Food Chemistry 126: 1330-1336 doi:10.1016/j.foodchem.2010.11.090

Radi, R., G. Peluffo, M. N. Alvarez, M. Naviliat, and A. Cayota. 2001. Unraveling peroxynitrite formation in biological systems. Free Radical Biology and Medicine 30: 463-488. doi:10.1016/S0891-5849(00)00373-7

Roja, G. 2008. Micropropagation and production of Camptothecin from in vitro plants of Ophiorrhiza rugosa var. decumbens. Natural Product Research 22(12): 1017-1023. doi:10.1080/14786410802006165

Sakato, K., and M. Misawa. 1974. Effects of chemical and physical conditions on growth of Camptotheca acuminata cell cultures. Agricultural and Biological Chemistry 38: 491-497. doi:10.1271/bbb1961.38.491

Sekiwa, Y., K. Kubota, and A. Kobayashi. 2000. Isolation of novel glucosides related to gingerdiol from ginger and their antioxidative activities. J. Agric. Food Chem. 48: 373-377. doi:10.1021/jf990674x

Wiedenfield, H., M. Furmanowa, E. Roeder, J. Guzewska, and W. Guzewska. 1997. Camptothecin and 10-hydroxy camptothecin in callus and plantlets of Camptotheca acuminata. Plant Cell Tissue and Organ Culture 49: 213-218. doi:10.1023/A:1005704429339

Wolfe, K. X. Wu, and R. H. Liu, 2003. Antioxidant activity of apple peel. J. Agric. Food Chem. 51: 609-614. doi:10.1021/jf020782a 